\title{
Scalable efficient expansion of mesenchymal stem cells in xeno free media using commercially available reagents
}

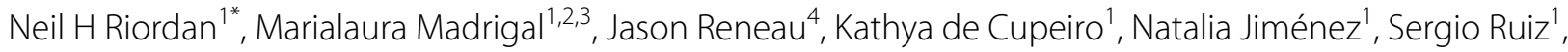
Nelsy Sanchez ${ }^{1}$, Thomas E Ichim ${ }^{5}$, Francisco Silva ${ }^{6}$ and Amit N Patel ${ }^{6}$

\begin{abstract}
Background: The rapid clinical translation of mesenchymal stem cells (MSC) has resulted in the development of cell-based strategies for multiple indications. Unfortunately one major barrier to widespread implementation of MSCbased therapies is the limited supply of fetal calf serum (FCS) used to expand cells to therapeutic numbers. Additionally, the xenogeneic element of fetal calf serum has been previously demonstrated to stimulate antibody mediated reactions and in some cases sensitization leading to anaphylaxis.
\end{abstract}

Method: XcytePLUS ${ }^{\mathrm{TM}}$ media, a human platelet lysate based product, was used to supplement the culture medium at $5,7.5$ and $10 \%$ and compared to fetal calf serum at 10\%, for human umbilical cord MSC expansion. Properties of the expanded cells were investigated.

Results: This study demonstrated equivalent or superior effects of human platelet lysate compared to standard FCS supplemented media, based on doubling rate, without loss of identity or function, as demonstrated with flow cytometry characterization. Differentiation into osteocytes, adipocytes and chondrocytes was comparable from cells expanded in either media supplement.

Conclusions: These data support the implementation of human platelet lysate supplemented media as an alternative to xenogeneic containing preparations which may lead to safer MSC products with therapeutic uses.

\section{Background}

Tissue culture originated with the work of Alexis Carrell at the beginning of the 20th century utilizing a variety of undefined media additives such as embryonic and muscle extracts mixed with saline plasma, which were able to maintain cardiac cells in vitro and allow for contractile function [1]. The introduction of fetal calf serum (FCS) as a media additive revolutionized the field of tissue culture and allowed for laboratories to maintain stable cell lines in vitro, which catalyzed major efforts in cancer research [2]. The concept of utilizing cells as therapeutics originated in the bone marrow transplant area, in which uncultured donor bone marrow stem cells were used for hematopoietic

\footnotetext{
*Correspondence: nhriordan@gmail.com

${ }^{1}$ Medistem Panama, Inc., Building 221, City of Knowledge, Clayton,

Panama City, Republic of Panama

Full list of author information is available at the end of the article
}

support to allow for high dose chemotherapy and radiation therapy [3]. The utilization of cellular immunotherapy, in the 1980s was the first major clinical experiments that required expansion of cells in vitro. In these early experiments, it was demonstrated that fetal calf serum posed some potential to induce adverse effects. For example, a study reported that syngeneic lymphocytes cultured in FCS and subsequently administered to HIV patients resulted in Arthus reaction and fever in recipients, which was associated with antibodies to FCS components [4]. Other studies have shown that both pre-existing natural, as well as inducible antibodies are present in patients that recognize various components of FCS [5-8]. Additionally, activation of both $\mathrm{T}$ cell and NK cell responses have been reported subsequent to stimulation with FCS $[9,10]$.

Mesenchymal stem cells (MSC) are fibroblast-shaped cells capable of multigenic differentiation into bone, fat and cartilage, as well as differentiation into neuronal, 
hepatic and pancreatic tissue [11]. A number of clinical trials have been performed utilizing MSC in conditions ranging from hepatic failure [12], type 1 diabetes [13], and stroke [14]. The majority of these clinical trials have utilized MSCs that are grown in FCS containing media. Overall safety has been demonstrated of MSC, as reported in a meta-analysis of clinical trials containing over 1,000 patients [15]. Interestingly, in these trials administration doses were 1-3 injections, thus substantially decreasing the possibility of sensitization. Despite this, some evidence of sensitization has been reported. Specifically, Le Blanc et al. demonstrated in 12 patients being administered bone marrow MSC for treatment of steroid resistant graft versus host disease (GVHD) the development of antibodies to fetal calf serum proteins as detected by ex vivo treatment of fetal calf proteins [16].

In order to overcome limitations associated with FCS, numerous groups have developed serum-free tissue culture media compositions for growing and expansion of MSC. Platelet derived growth factor (PDGF) is a potent cellular mitogen and has been reported to be a significant component of FCS allowing for cellular proliferation in vitro [17]. Since platelet lysate contains significant concentrations of PDGF, as well as numerous other mitogenic factors [18], investigators have utilized this as a potential substitute for FCS. In 2006 Müller et al. reported that bone marrow MSC cultures can be initiated and maintained in media in which FCS was substituted with platelet lysate [19]. The MSC grown in platelet lysate substituted media retained both differentiation, as well as immune modulatory activity. Numerous other studies have demonstrated that various platelet lysate preparations are capable of maintaining or increasing proliferation of bone marrow MSC as a substitute for FCS [20-35]. Another report on 213 patients treated with autologous BM MSC cultured in platelet lysate reported no adverse reactions subsequent to intradisc and intrajoint administration [36]. Some characterization has occurred of active components of platelet lysate. Specifically, antibody blocking studies have shown that up to $75 \%$ inhibition of MSC proliferation in response to platelet lysate was achieved with a combination of anti-bFGF + anti-PDGF-BB and anti-bFGF + antiTGF- $\beta 1+$ anti-PDGF-BB. Interestingly, various combinations of recombinant PDGF-BB, bFGF and TGF- $\beta 1$ were not sufficient to promote cell proliferation, implying some components still remain unknown [37].

Despite advancements that have been reported utilizing platelet lysate, several obstacles still remain for large-scale commercial application, namely: (a) establishing the role that platelet lysate plays in increasing antiinflammatory activity of MSC when compared to culture in FCS [38, 39]; (b) significant variation in MSC cultures depending on platelet donor profiles [40], with age being a contributing factor [41]; and (c) institution-specific proprietary methods for large-scale commercial production of platelet lysate, and the roles of factors such as heparin [42], or fibrinogen [39], concentration post largescale production. Addressing these points will allow for a better standardized method for large-scale commercial production.

Here we present data using a commercially available platelet-lysate based media, XcytePLUS ${ }^{\mathrm{m}}$, to culture human umbilical cord's Wharton's Jelly MSC (WJ-MSC) in comparison to media containing FCS. Additionally, the culture system described is completely free of xenogeneic components in that dissociation media did not contain bovine trypsin. We report equivalent or superior proliferation, and differentiation activity of WJ-MSC cultured in XcytePLUS ${ }^{\mathrm{mm}}$ media as compared to FCS.

\section{Methods}

\section{Cells and tissue culture}

Wharton's Jelly mesenchymal stem cells were isolated from healthy donors according to Secco et al. [43]. Briefly, umbilical cords of minimum $25 \mathrm{~cm}$ long were dissected, and cut in pieces of $8 \mathrm{~cm}$, and they were digested using Collagenase 1.67\% (Sigma C9891) during $60 \mathrm{~min}$ at $37^{\circ} \mathrm{C}$. Tissue was washed twice and all supernatant was centrifuged to collect the pellet and then plated at $1 \times 10^{4} \mathrm{cells} / \mathrm{cm}^{2}$. Cells were cultured using MEM alpha (Life 32561102) supplemented with $2 \mathrm{mM}$ GlutaMax (Life 35050-079) and 10\% FCS (Life 16000044).

All Isolated MSCs were frozen in Passage 2. Immunophenotype characterization was performed and based on those results, four lots were selected from a stock of cells to continue the experiments.

MSCs were thawed and plated into 6 well plates ( 6 wells per treatment), $5 \times 10^{4}$ cells/well, using XcytePLUS ${ }^{\mathrm{mm}}(\mathrm{iBi}-$ ologics XPGS-001-500) (5, 7.5, and 10\%) or 10\% FCS supplemented media in two different laboratories. Cells were grown up to $80-90 \%$ confluence, then passaged using Tryple Express (Life Technologies), splits were 1:6, up to passage 6 . Cell counts were performed every passage before re-plating to determine cell-doubling time. Finally, cells were frozen for further analysis of membrane markers expression and differentiation.

\section{Flow cytometry}

Flow cytometry was performed using Guava EasyCyte Mini (Millipore) flow cytometer. Antibodies CD105, CD73, CD90, CD34, CD45 were purchased from (BD pharmingen), isotype controls for FITC and RPE were utilized. 


\section{Doubling rate}

Doubling rate of the cells was assessed by counting the cells in every passage. Number of doublings was calculated by the equation:

$$
\mathrm{X}=\left(\log (\mathrm{n})-\log \left(\mathrm{n}_{0}\right)\right) / \log (2),
$$

$\mathrm{n}=$ number of cells obtained, $\mathrm{n}_{0}=$ number of cells plated.

\section{Statistical analysis}

For the statistical analysis, comparison of averages were made using GraphPad (Prism 6) software. Two-way ANOVA with Tukey test was used for doublings per day, cumulative number of cells and characterization analysis. One-way ANOVA was used for inter-laboratory analysis. In all tests a confidence interval of $95 \%$ was used.

\section{Differentiation assays}

Two lots were used for the differentiation assay. Briefly, 24 well plates were used and differentiation medium was prepared using DMEM low glucose, without phenol red (Life Technologies) supplemented with $2 \mathrm{mM}$ glutaMax and $10 \%$ FCS. Adipogenesis media was supplemented with $1 \mu \mathrm{M}$ dexamethasone, $500 \mu \mathrm{M}$ 3-isobutyl-1-methylxantine, $60 \mu \mathrm{M}$ indometacine, $5 \mu \mathrm{g} / \mathrm{ml}$ insulin. Chondrogenesis media with $0.1 \mu \mathrm{M}$ dexamethasone, $50 \mu \mathrm{M}$ ascorbate-2-phosphate, $1 \mathrm{mM}$ sodium pyruvate, $1 \%$ ITS Premix, 10 ng/ml TGF- $\beta 1$, and Osteogenesis media with $0.1 \mu \mathrm{M}$ dexamethasone, $50 \mu \mathrm{M}$ ascorbate-2-phosphate, $10 \mathrm{mM} \beta$-glycerophosphate. After 21 days, alcian blue, alizarin red and oil red $\mathrm{O}$ were used to stain chondrocytes, osteocytes and adipocytes, respectively.

\section{Results}

\section{Doubling rate superior with WJ-MSC cultured in XCyte}

\section{Media versus FCS}

WJ-MSC after 5 passages were plated in media containing 5, 7.5 and $10 \%$ XcytePLUS ${ }^{\mathrm{mm}}$, or 10\% FCS supplemented media and cultured for 9 days. Morphological differences were not found between the treatment groups (Figure 1).
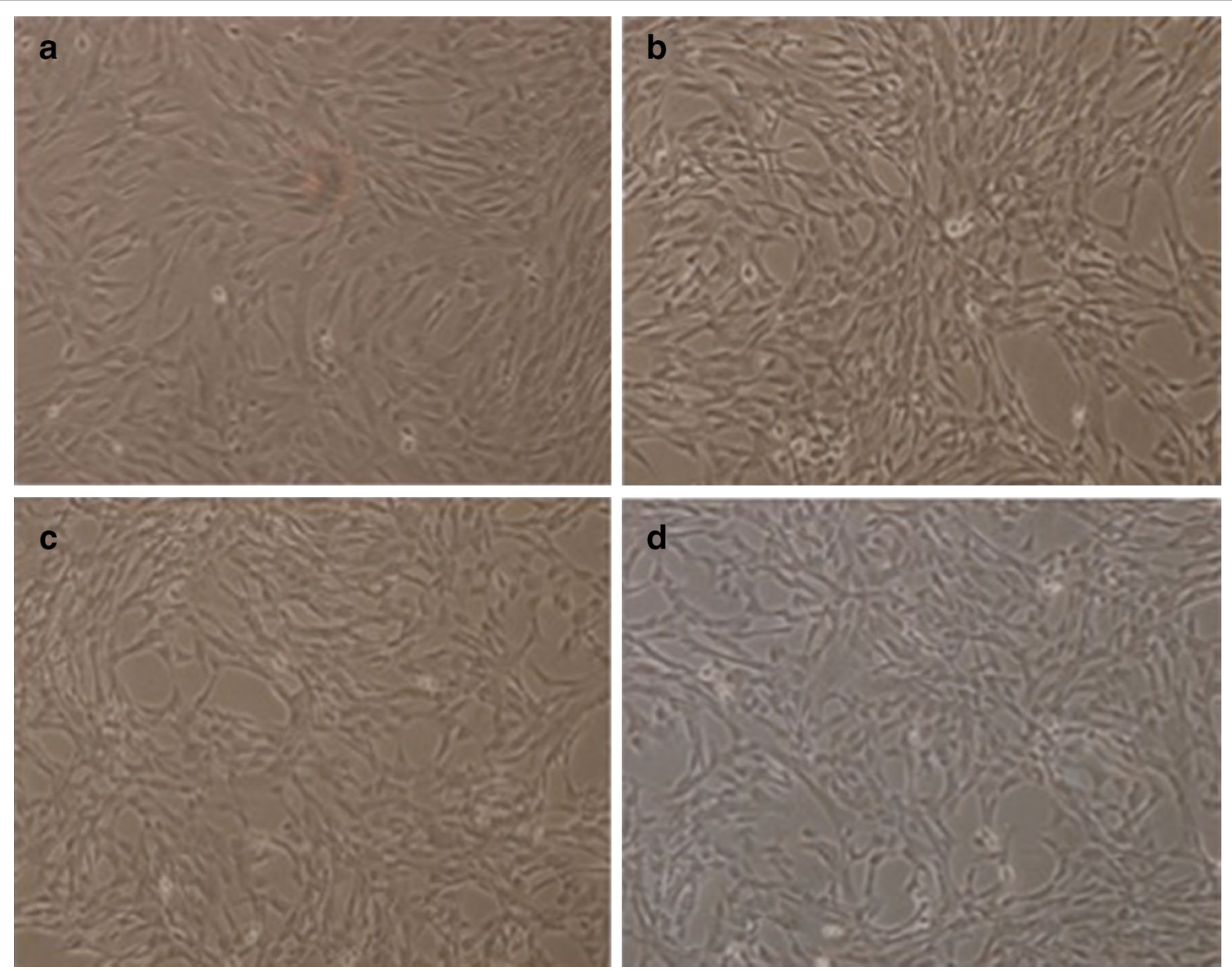

Figure 1 Morphology of WJ-MSC is not altered by supplementation of culture media with XcytePLUS ${ }^{\text {TM }}$ compared to Fetal Calf Serum (FCS). 10X inverted phase contrast microscope images of WJ-MSC cultured in a 10\% FCS, b 5\% XcytePLUS ${ }^{\mathrm{TM}}$, c 7.5\% XcytePLUS ${ }^{\mathrm{TM}}$ and d $10 \%$ XcytePLUS ${ }^{\mathrm{TM}}$ on passage 5. 
Significantly higher number of WJ-MSC were collected on day 9 with the $10 \%$ XcytePLUS $^{\text {mo }}$ supplemented media (average $1.4 \times 10^{7}$ ) as compared to $10 \%$ FCS media (average $\left.7.5 \times 10^{6}\right)(\mathrm{p}<0.05)$. Average numbers are represented in Figure 2. Furthermore, population doublings in 9 days were 8.37 for cells supplemented with $10 \%$ XcytePLUS $^{\text {tm }}$ and 7.29 using 10\% FCS. Doublings per day did not show statistical difference when different lots of XcytePLUS ${ }^{\text {Tw }}$ were used (Figure 3). Furthermore, doubling rate experiments performed on the same four lots in different laboratories did not show substantial differences (Figure 4).

\section{Maintenance of MSC phenotype}

In order to assess whether WJ-MSC were not altered by culturing in XcytePLUS ${ }^{\mathrm{m}}$ media from a phenotypic perspective, flow cytometric analysis was performed at the

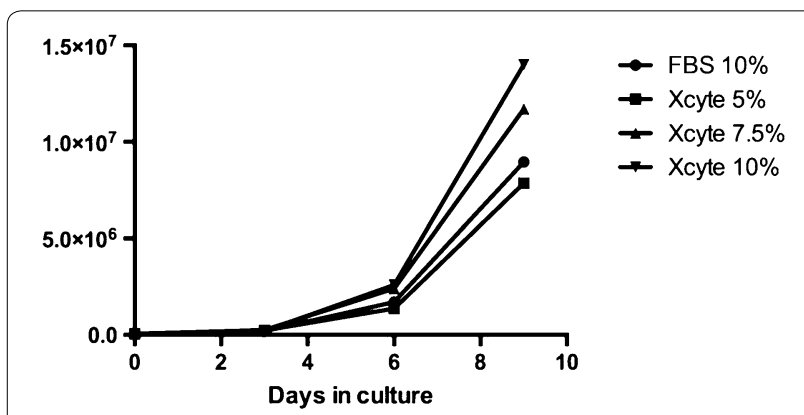

Figure 2 Superior expansion of WJ-MSC by culture media supplemented with X cytePLUS $^{\mathrm{TM}}$ compared to Fetal Bovine/Calf Serum (FBS). Passage 5 WJ-MSC were cultured in media supplemented with the indicated concentrations of XcytePLUS ${ }^{\mathrm{TM}}$ or FBS. Cell quantification was performed by manual counting as described in "Methods". The average represent four different lots run in two different laboratories.

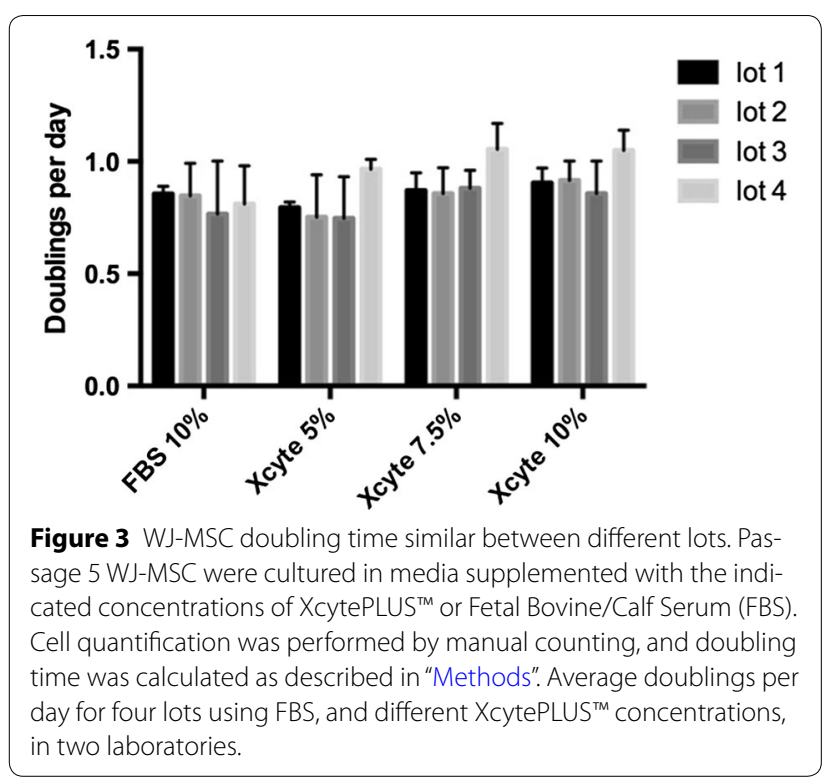

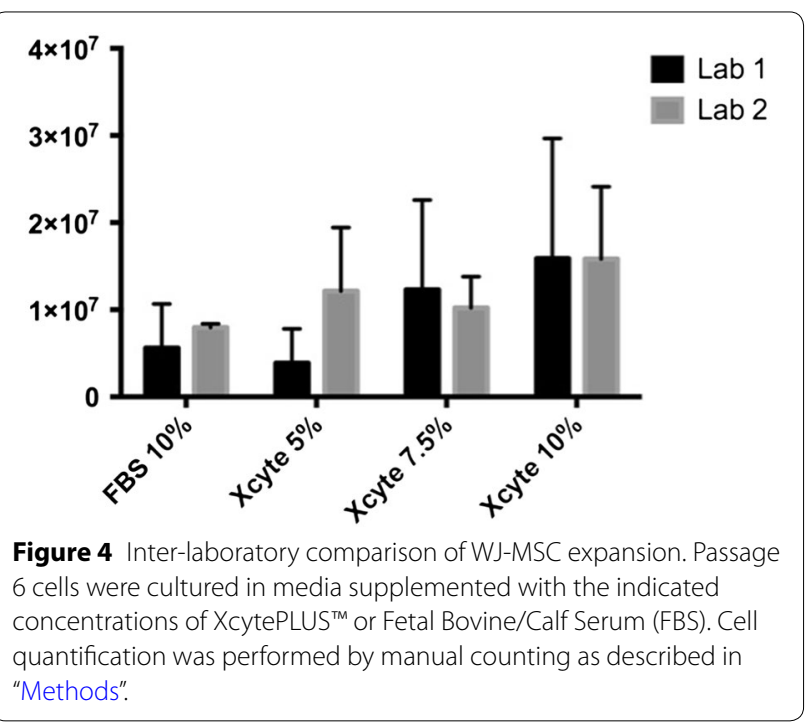

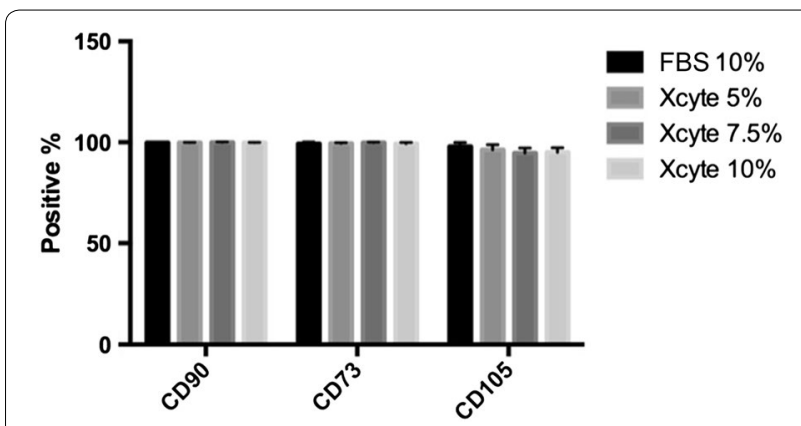

Figure 5 Flow cytometry characterization of XcytePLUS ${ }^{\mathrm{TM}}$ versus Fetal Bovine/Calf Serum (FBS) Cultured WJ-MSC. Flow cytometric analysis of indicated MSC markers was performed as described in "Methods". Marker expression was quantified as percentage positive events detected from gated cells.

completion of 9 days of culture. As seen in Figure 5, cells maintained the markers of CD105+, CD73+, CD90+ throughout the culture period, which was not affected significantly by the type of media utilized. CD34 and CD45 expression was maintained negative, consistent with classical MSC phenotype.

\section{Differentiation potential}

Cells at passage 6 grown under $5,7.5$ or $10 \%$ XcytePLUS $^{\text {mo }}$ Media or 10\% FCS were exposed to adipogenic, osteogenic and chondrogenic differentiation conditions. As seen in Figure 6, differentiation ability of WJ-MSC was not affected by XcytePLUS ${ }^{\text {tw }}$ or FCS supplementation.

\section{Discussion}

The current findings provide for the first time data on reproducibility of a commercially available xenogenic 


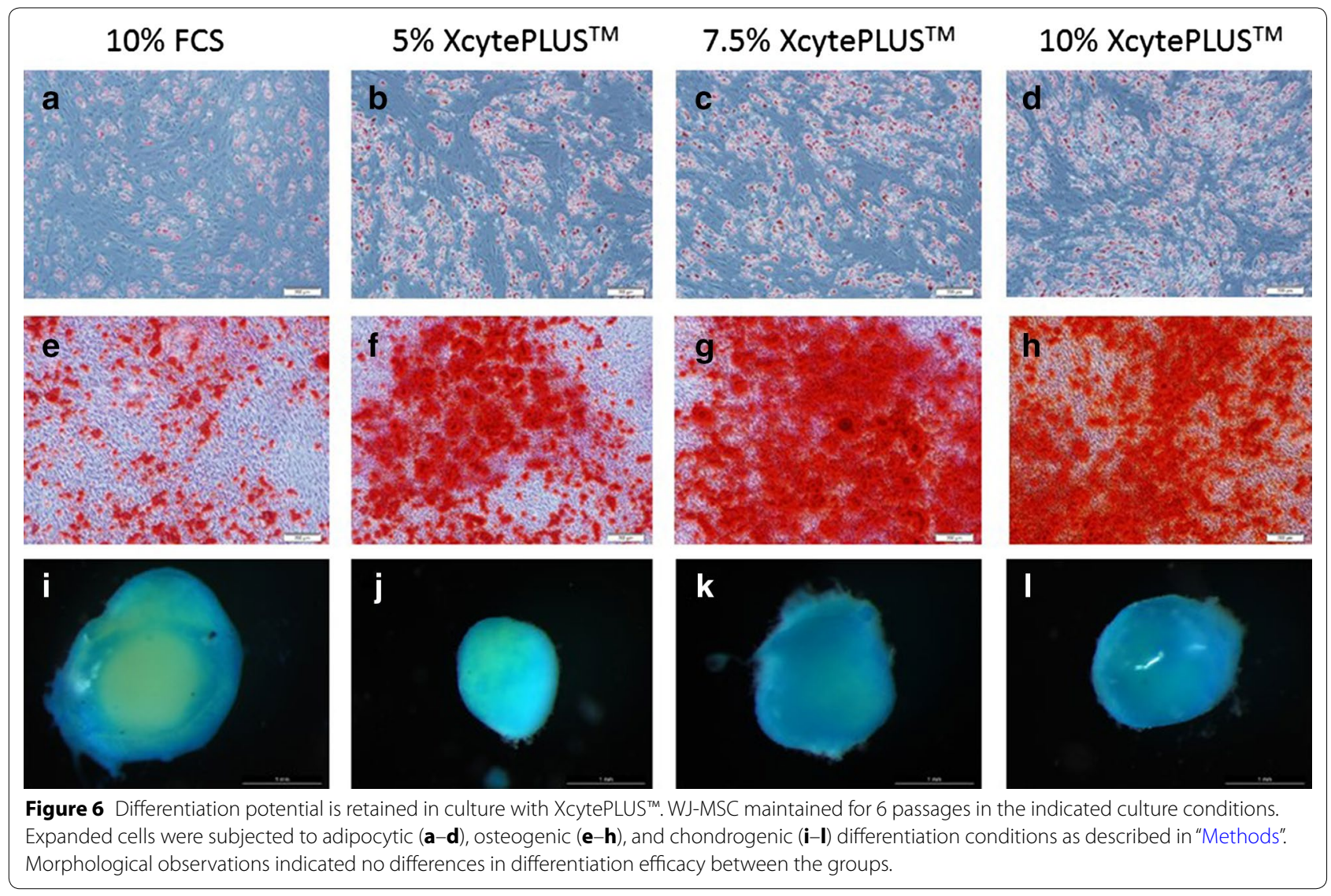

free media supplement and cell dissociation technique assessed across WJ-MSC donors. Equivalent or superior induction of cell proliferation was noted, as well as retention of classical MSC surface markers for 6 passages. Reproducibility of results between two independent laboratories was demonstrated.

Currently there is substantial controversy in the area of platelet lysate based cultures with various investigators providing contradictory results. Furthermore the field is complicated by lack of widespread access to various proprietary reagents utilized in the manufacture of the platelet lysate. Specifically, conditions such as concentration of heparin, fibronectin or donor characteristics all contribute to variability of product. XcytePLUS ${ }^{\text {Tax }}$ media is commercially available and is based on stringent characterized donors with large lots, thereby decreasing lot to lot variability.

Even though it has been reported that platelet lysate substitution for FCS results in a lower ability to differentiate into both adipogenic and osteogenic lineages, our data does not support this finding [44]. Due to enhanced proliferation rates with platelet lysate media, population doublings could be higher compared to FCS supplemented media. We have demonstrated that population doublings should be controlled so that the cells can retain differentiation ability.

\section{Conclusions}

The large-scale production of clinical grade MSCs demands a xeno-free standardized culture system. Feasibility of the use of XcytePLUS ${ }^{\text {ma }}$ was demonstrated with consistent results in proliferation rate, characterization and differentiation potential. XcytePLUS ${ }^{\mathrm{mm}}$ is a pooled human platelet lysate product, which allows for a commercial therapeutic MSC product.

\section{Author's contributions}

NHR and MM conceived and designed the experiment. NHR, MM, JR, KC, NJ, $S R$, NS, TEI, FS, ANP were involved in experimental design, execution of experiments, and writing of the manuscript. All authors read and approved the final manuscript.

\section{Author details}

${ }^{1}$ Medistem Panama, Inc., Building 221, City of Knowledge, Clayton, Panama City, Republic of Panama. ${ }^{2}$ Indicasat AIP Panama, City of Knowledge, Rep. of Panama. ${ }^{3}$ Acharya Nagarjuna University, Guntur, India. ${ }^{4}$ Amniotic Therapies, LLC, Farmers Branch, TX, USA. ${ }^{5}$ Coma Research Institute, La Jolla, CA, USA. ${ }^{6}$ University of Utah School of Medicine, Salt Lake City, UT, USA. 


\section{Acknowledgements}

This work was funded by internal grants from the Department of Cardiothoracic Surgery at the University of Utah, Salt Lake City, Utah.

\section{Compliance with ethical guidelines}

\section{Competing interests}

The authors declare that they have no competing interests.

Received: 14 April 2015 Accepted: 3 June 2015

Published online: 17 July 2015

\section{References}

1. Carrel A (1912) On the permanent life of tissues outside of the organism. J Exp Med 15(5):516-528

2. Shodell M, Rubin H, Gerhart J (1972) Neutralization of growth-inhibitory material present in calf serum by conditioning factors elaborated by chick embryo cells in culture. Exp Cell Res 74(2):375-382

3. Thomas ED (1983) Bone marrow transplantation. A lifesaving applied art. An interview with E. Donnall Thomas, MD. JAMA 249(18):2528-2536

4. Selvaggi TA, Walker RE, Fleisher TA (1997) Development of antibodies to fetal calf serum with arthus-like reactions in human immunodeficiency virus-infected patients given syngeneic lymphocyte infusions. Blood 89(3):776-779

5. Irie RF, Irie K, Morton DL (1974) Natural antibody in human serum to a neoantigen in human cultured cells grown in fetal bovine serum. J Natl Cancer Inst 52(4):1051-1058

6. Macy E et al (1989) Anaphylaxis to infusion of autologous bone marrow: an apparent reaction to self, mediated by IgE antibody to bovine serum albumin. J Allergy Clin Immunol 83(5):871-875

7. Mackensen A, Drager R, Schlesier M, Mertelsmann R, Lindemann A (2000) Presence of IgE antibodies to bovine serum albumin in a patient developing anaphylaxis after vaccination with human peptide-pulsed dendritic cells. Cancer Immunol 49(3):152-156

8. Kadri N, Potiron N, Ouary M, Jegou D, Gouin E, Bach JM et al (2007) Fetal calf serum-primed dendritic cells induce a strong anti-fetal calf serum immune response and diabetes protection in the non-obese diabetic mouse. Immunol Lett 108(2):129-136

9. Forni $G$, Green I (1976) Heterologous sera: a target for in vitro cell-mediated cytotoxicity. J Immunol 116(6):1561-1565

10. Lauer SJ, Finlan J, Borella LD, Piaskowski VD, Casper JT (1983) In vitro enhancement of peripheral blood mononuclear cell natural killer activity following short term incubation with fetal calf serum. J Clin Lab Immunol 12(2):105-110

11. Arien-Zakay H, Lazarovici P, Nagler A (2010) Tissue regeneration potential in human umbilical cord blood. Best Pract Res Clin Haematol 23(2):291-303

12. Obermajer N, Popp FC, Johnson CL, Benseler V, Dahlke MH (2014) Rationale and prospects of mesenchymal stem cell therapy for liver transplantation. Curr Opinion Organ Transplant 19(1):60-64

13. Hu J, Yu X, Wang Z, Wang F, Wang L, Gao H et al (2013) Long term effects of the implantation of Wharton's jelly-derived mesenchymal stem cells from the umbilical cord for newly-onset type 1 diabetes mellitus. Endocrine J 60(3):347-357

14. Huo W, Liu X, Tan C, Han Y, Kang C, Quan W et al (2014) Stem cell transplantation for treating stroke: status, trends and development. Neural Regen Res 9(17):1643-1648. doi:10.4103/1673-5374.141793

15. Kaplan JM, Youd ME, Lodie TA (2011) Immunomodulatory activity of mesenchymal stem cells. Curr Stem Cell Res Ther 6(4):297-316

16. Sundin M, Ringden O, Sundberg B, Nava S, Gotherstrom C, Le Blanc K (2007) No alloantibodies against mesenchymal stromal cells, but presence of anti-fetal calf serum antibodies, after transplantation in allogeneic hematopoietic stem cell recipients. Haematologica 92(9):1208-1215

17. Bowen-Pope DF, Ross R (1984) Platelet-derived growth factor. Clin Endocrinol Metab 13(1):191-205

18. Eastment CT, Sirbasku DA (1980) Human platelet lysate contains growth factor activities for established cell lines derived from various tissues of several species. In Vitro 16(8):694-705
19. Muller I, Kordowich S, Holzwarth C, Spano C, Isensee G, Staiber A et al (2006) Animal serum-free culture conditions for isolation and expansion of multipotent mesenchymal stromal cells from human BM. Cytotherapy 8(5):437-444. doi:10.1080/14653240600920782

20. Lange C, Cakiroglu F, Spiess AN, Cappallo-Obermann H, Dierlamm J, Zander AR (2007) Accelerated and safe expansion of human mesenchymal stromal cells in animal serum-free medium for transplantation and regenerative medicine. J Cellular Physiol 213(1):18-26. doi:10.1002/ jcp.21081

21. Schallmoser K, Bartmann C, Rohde E, Reinisch A, Kashofer K, Stadelmeyer E et al (2007) Human platelet lysate can replace fetal bovine serum for clinical-scale expansion of functional mesenchymal stromal cells. Transfusion 47(8):1436-1446. doi:10.1111/j.1537-2995.2007.01220.x

22. Capelli C, Domenghini M, Borleri G, Bellavita P, Poma R, Carobbio A et al (2007) Human platelet lysate allows expansion and clinical grade production of mesenchymal stromal cells from small samples of bone marrow aspirates or marrow filter washouts. Bone Marrow Transpl 40(8):785-791. doi:10.1038/sj.bmt.1705798

23. Carrancio S, Lopez-Holgado N, Sanchez-Guijo FM, Villaron E, Barbado V, Tabera $S$ et al (2008) Optimization of mesenchymal stem cell expansion procedures by cell separation and culture conditions modification. Experimental Hematol 36(8):1014-1021

24. Salvade A, Della Mina P, Gaddi D, Gatto F, Villa A, Bigoni M et al (2010) Characterization of platelet lysate cultured mesenchymal stromal cells and their potential use in tissue-engineered osteogenic devices for the treatment of bone defects. Tissue Eng Part C 16(2):201-214. doi:10.1089/ ten.TEC.2008.0572

25. Bieback K, Hecker A, Kocaomer A, Lannert H, Schallmoser K, Strunk D et al (2009) Human alternatives to fetal bovine serum for the expansion of mesenchymal stromal cells from bone marrow. Stem Cells 27(9):2331-2341

26. Crespo-Diaz R, Behfar A, Butler GW, Padley DJ, Sarr MG, Bartunek J et al (2011) Platelet lysate consisting of a natural repair proteome supports human mesenchymal stem cell proliferation and chromosomal stability. Cell Transplant 20(6):797-811

27. Xia W, Li H, Wang Z, Xu R, Fu Y, Zhang X et al (2011) Human platelet lysate supports ex vivo expansion and enhances osteogenic differentiation of human bone marrow-derived mesenchymal stem cells. Cell Biol Int 35(6):639-643

28. Kinzebach S, Bieback K (2013) Expansion of mesenchymal stem/stromal cells under xenogenic-free culture conditions. Adv Biochem Eng Biotechnol 129:33-57

29. Warnke PH, Humpe A, Strunk D, Stephens S, Warnke F, Wiltfang J et al (2013) A clinically-feasible protocol for using human platelet lysate and mesenchymal stem cells in regenerative therapies. J Craniomaxillofac Surg 41(2):153-161

30. Fekete N, Rojewski MT, Furst D, Kreja L, Ignatius A, Dausend J et al (2012) GMP-compliant isolation and large-scale expansion of bone marrowderived MSC. PloS One 7(8):e43255

31. Bernardi M, Albiero E, Alghisi A, Chieregato K, Lievore C, Madeo D et al (2013) Production of human platelet lysate by use of ultrasound for ex vivo expansion of human bone marrow-derived mesenchymal stromal cells. Cytotherapy 15(8):920-929

32. Mojica-Henshaw MP, Jacobson P, Morris J, Kelley L, Pierce J, Boyer M et al (2013) Serum-converted platelet lysate can substitute for fetal bovine serum in human mesenchymal stromal cell cultures. Cytotherapy 15(12):1458-1468

33. Shanskii YD, Sergeeva NS, Sviridova IK, Kirakozov MS, Kirsanova VA, Akhmedova SA et al (2013) Human platelet lysate as a promising growthstimulating additive for culturing of stem cells and other cell types. Bull Exp Biol Med 156(1):146-151

34. Iudicone P, Fioravanti D, Bonanno G, Miceli M, Lavorino C, Totta P et al (2014) Pathogen-free, plasma-poor platelet lysate and expansion of human mesenchymal stem cells. J Transl Med 12:28

35. Shih DT, Burnouf T (2014) Preparation, quality criteria, and properties of human blood platelet lysate supplements for ex vivo stem cell expansion. N Biotechnol

36. Centeno CJ, Schultz JR, Cheever M, Robinson B, Freeman M, Marasco W (2010) Safety and complications reporting on the re-implantation of culture-expanded mesenchymal stem cells using autologous platelet lysate technique. Curr Stem Cell Res Ther 5(1):81-93 
37. Fekete N, Gadelorge M, Furst D, Maurer C, Dausend J, Fleury-Cappellesso S et al (2012) Platelet lysate from whole blood-derived pooled platelet concentrates and apheresis-derived platelet concentrates for the isolation and expansion of human bone marrow mesenchymal stromal cells: production process, content and identification of active components. Cytotherapy 14(5):540-554

38. Abdelrazik H, Spaggiari GM, Chiossone L, Moretta L (2011) Mesenchymal stem cells expanded in human platelet lysate display a decreased inhibitory capacity on T- and NK-cell proliferation and function. Eur J Immunol 41(11):3281-3290

39. Copland IB, Garcia MA, Waller EK, Roback JD, Galipeau J (2013) The effect of platelet lysate fibrinogen on the functionality of MSCs in immunotherapy. Biomaterials 34(32):7840-7850

40. Horn P, Bokermann G, Cholewa D, Bork S, Walenda T, Koch C et al (2010) Impact of individual platelet lysates on isolation and growth of human mesenchymal stromal cells. Cytotherapy 12(7):888-898
41. Lohmann M, Walenda G, Hemeda H, Joussen S, Drescher W, Jockenhoevel $S$ et al (2012) Donor age of human platelet lysate affects proliferation and differentiation of mesenchymal stem cells. PloS One 7(5):e37839

42. Hemeda H, Kalz J, Walenda G, Lohmann M, Wagner W (2013) Heparin concentration is critical for cell culture with human platelet lysate. Cytotherapy 15(9):1174-1181

43. Secco M, Zucconi E, Vieira NM, Fogaca LL, Cerqueira A, Carvalho MD et al (2008) Multipotent stem cells from umbilical cord: cord is richer than blood! Stem Cells 26(1):146-150

44. Ben Azouna N, Jenhani F, Regaya Z, Berraeis L, Ben Othman T, Ducrocq E et al (2012) Phenotypical and functional characteristics of mesenchymal stem cells from bone marrow: comparison of culture using different media supplemented with human platelet lysate or fetal bovine serum. Stem Cell Res Ther 3(1):6

\section{Submit your next manuscript to BioMed Central and take full advantage of:}

- Convenient online submission

- Thorough peer review

- No space constraints or color figure charges

- Immediate publication on acceptance

- Inclusion in PubMed, CAS, Scopus and Google Scholar

- Research which is freely available for redistribution

Submit your manuscript at www.biomedcentral.com/submit 